\title{
New Method of Machining Teeth on Unspecialised Machine Tools
}

\author{
Rafal TALAR, Piotr JABLONSKI, Wojciech PTASZYNSKI
}

\begin{abstract}
In the present work, the authors describe elaborated method of machining teeth with the use of unspecialized machine tools. In the first part of the work the need to develop such a method has been shown and the drawbacks of the known methods have been indicated. Further part of the work describes the process of mathematical modelling the purpose of which was to determine the tool paths during machining. Next, the kinetics of teeth machining with the use of a universal CNC milling centre is presented. Further on, the operation of the algorithm, the user's interface of the elaborated software and the parameters influencing the machining process have been shown. In the final part of the work, the results of examination of the obtained details have been shown on a gear wheel as an example. The origin of machining errors and their significance has been discussed. In conclusions, summary of obtained results is presented. In last paragraphs, authors discuss machining accuracy of developed method, and application possibilities of described method are emphasised as well. Performed verification proved that developed method is capable of machining gears of quality comparable with these machined with specialised equipment.
\end{abstract}

Keywords: CNC machine tools; LabView; machine tool accuracy; teeth accuracy; teeth machining

\section{INTRODUCTION}

The present, modern trends which can be observed in production organization often aim at high elasticity of manufacturing. Increasing part of the market the producers of machine parts and subassemblies belong to enterprises possessing vast and various possibilities in the scope of offered technologies. The possibility to use the technological resources at one's disposal in the realisation of various production tasks appears to be a great advantage in competition on the dynamic market of machine part producers.

Special technologies of forming teeth, including the orbital methods, are well known and widely applied. However, one of the major drawbacks of the known methods of teeth forming, such as, for example, chiselling, orbital milling, shaving, grinding, etc. is that the used machines and tools cannot be used in other technological operations. What is more, a change of the parameters of the teeth being machined often requires expensive refitting, purchase of other tools and performing of a number of technological tests involved in the change of production

In connection with the above, it is natural that endeavours have been made to use numerically controlled machines in complete teeth machining [1-4]. Methods using multiaxial machining centres and modern systems of computer aided manufacturing are applied [5]. Majority of the described methods assume the use of machines, tools and operation modes which are used in machining of moulds and dies. According to the authors describing such solutions, due to similar requirements (high execution accuracy and low surface roughness) and similar materials (hard-to-machine alloy steels with raised hardness and fatigue resistance), it is possible to apply the methods known from mould and die machining in machining teeth. Among the known solutions, the ones using full carbide slotting mills prevail [6]. The use of universal tools and machines significantly extends the possibilities of the technological backing and the use of CAM system in designing machining enables the technology for toothed elements differing in the teeth parameters to be prepared in a simple way $[7,8]$.The economic factors are the main advantages of the application of universal tools and machines in machining of teeth named by the authors [9, 10]. The investigation published by [11] was focused on complex assessment of the errors of teeth execution by means of slotting mills and spherical cutters on a universal milling centre. According to the author, the final accuracy is strongly influenced by the complex trajectory of the tool, depending on the selected machining strategy. Due to the fact that in many of the teeth machining methods under discussion, the surface of the teeth is considered as a complex spatial surface, the machine tool works in several axes at a time. Such a case of machining leads to reduction of the machine rigidity and to combination of many component errors of positioning of each of the active axes [12, 13]. They describe the method of error measurement and assessment of accuracy of cylindrical teeth machined on CNC machines. The authors deal with the subjects of outline errors. The methods of measurements of straight cylindrical gears and bevel gears, as well as the ways of assessment of machining accuracy on CNC machines are described by [14]. The increasing need to improve the service properties of machine parts, including gear teeth, necessitates constant development of machining technologies aiming at reduction of surface roughness and at controlling the properties of the top layer depending on the application [15-19].

The methods using universal machines and tools have undeniable advantages, but also a number of drawbacks which prevent their wider application. The major ones, in the authors' opinion are the problems involved in obtaining close execution accuracy as in the case of the dedicated methods. When considering machining gear wheels with standard slotting mills, the rigidity of the tools used becomes a serious problem. The problem is particularly related to small module pitch teeth for it is to be kept in mind that the diameter of the tools used is limited by the dimensions of the teeth space bottom. The tool deflection can be limited to an extent, for example, by reduction of the removed layer cross section, which, however, results in reduction of the profitability of the technology due to the extension of machine times. 
In order to limit the problems related to the small rigidity of tools, a method using an interlocking mill has been proposed. This type of tool should, in the authors' opinion, be more rigid than the slotting mills. The next stages of the elaboration of the technology were the determination of the tool geometry, machining kinetics and determination of the generation of the NC controlling program. It has been assumed that the method being elaborated should make it possible to machine involute gear wheels, straight tooth ones and helical tooth ones

\section{THE PROCESS OF MATHEMATICAL MODELLING}

The design of a milling head with exchangeable rhombus multi-edge cutting plates made of sintered carbide with small cutter tip angle, close to 35, characteristic of standardised plates with the geometry designated with the symbol of $\mathrm{V}$. Reduction of the cutter tip angle allows for machining teeth spaces with small module, however, due to the way of the plate fixing and to the growing liability to the edge chipping, the values of that angle cannot be too small. In Fig. 1, one can see the tool of the author's design with 12 special cutting edges made of sintered carbide with not standardised geometry.

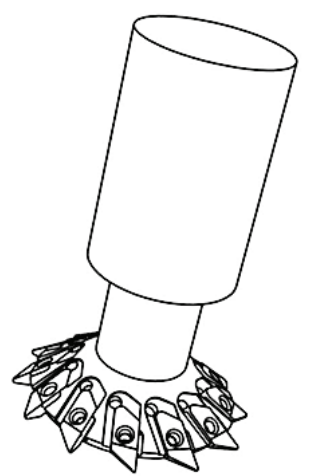

Figure 1 Milling head with 12 special cutting plates

The elaboration of an algorithm which would generate control program for teeth machining had to be started with determination of a mathematical model to determine the subsequent positions of the tool. The mathematical model was based on the assumption that the side surfaces of the teeth are formed by the cutting edge corner and the straight section of the cutting edge, tangent to the tooth outline curve.

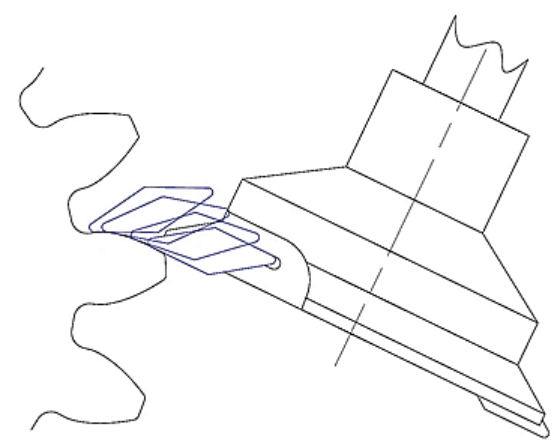

Figure 2 Sequence of the tool positions during machining with the assumed kinetics
One of the initial stages of the mathematical modelling was the determination of the points of tangency of the tool outline with the side surface of the tooth being machined. The defined points of tangency determine the later position of the subsequent tool passes during machining. Fig. 2 shows the subsequent positions of the tool in the course of machining one side of a tooth.

One of the major problems of the mathematical modelling under discussion is the distribution of the subsequent points of tangency of the cutting edge to the outline being machined. In order to make it possible to control the distribution of the tangency points, the concentration coefficient, $K$, has been put into the mathematical model which coefficient enables linear change of the length of the lines connecting the subsequent points of tangency. Alteration of the value of the concentration coefficient enables the sections to be shortened in the vicinity of the tooth point (the coefficient higher than 1) or in the vicinity of its root (the coefficient lower than 1).

Due to the discontinuous division of the nominal outline into machined sections (between the neighbouring points of tangency), a phenomenon of theoretical outline lobbing appears, related to the location of the points of tangency. Introduction of the concentration coefficient and the possibility of modifying it allow us to control the value of the theoretical outline lobbing even prior to the generation of the controlling program. The values of the theoretical outline lobbing and its variation along the tooth outline for various values of the concentration coefficient, $K$, and resolution of interpolation directly influencing the quality of $N$, can be seen in Fig. 3. Different numbers of the tangency points (resolution of interpolation, $N$ ) directly influence the quality of the interpolation of the tooth outline curve. As the number of the points of tangency increases, the number of the sections interpolating the tooth outline grows, too, and their length decreases, which significantly improves the accuracy of the outline projection. $K=1.15$ is the value considered to give the best effects. The solution is justified by the fact that, for this value, the minimum lobbing occurs in the vicinity of the pitch diameter of the gear wheel, i.e. in the area where sliding does not occur and the oil film has the smallest thickness [20]. It has been determined that, at the place where the oil film thickness is the smallest, obtaining the lowest roughness will be of crucial importance to increase the teeth resistance to wear. In addition to the theoretical outline lobbing, the distribution of the points of tangency on the teeth outline will influence the area of the section of the layer removed in one pass and on the maximum depth of cutting, ap. The influence of the concentration coefficient, $K$, on the section of the removed layer is shown in Fig. 4 . In the figure, one can see that, for $K=1.15$, when moving away from the gear wheel base diameter, the variability of the area of the removed layer section is a relationship closer to linear one than in the other case where $K=1$. It should be mentioned that the area of the layer removed in one pass will strongly influence the tool deformation. The problem will be discussed in the further part of the present work. 

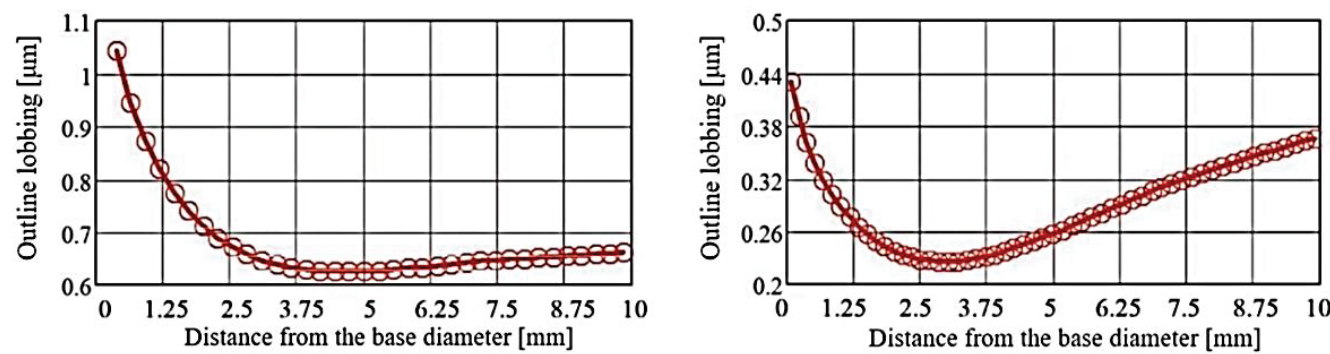

$K=1 ; N=40$

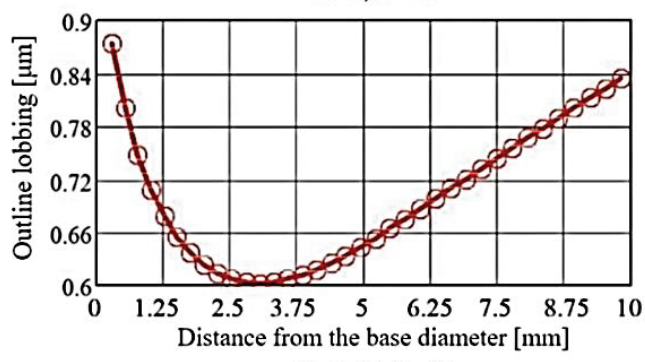

$K=1.15 ; N=40$

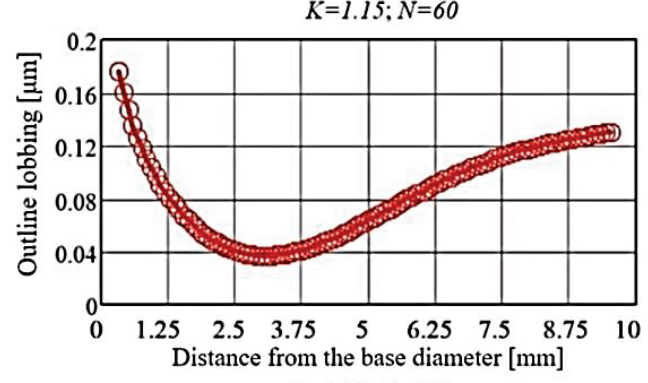

$K=1.15 ; N=100$

Figure 3 Variability of the theoretical lobbing as a function of the distance from the base diameter of teeth for various values of the concentration coefficient, $K$, and resolution of the outline interpolation, $N$.
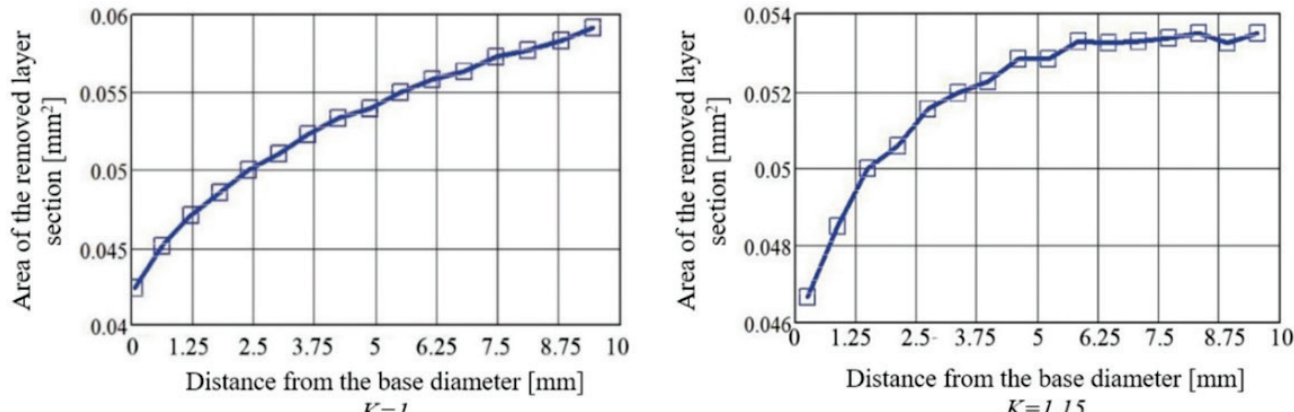

Figure 4 Variation of the removed layer area as a function of the teeth base diameter for various values of the concentration coefficient, $K$

The next important stage of mathematical modelling was the determination of the tool positions during linear motion, the effect of which is forming the actual tooth outline. It is worth stating that, during machining, the tool performs only linear motion tangent to the tooth outline, with simultaneous rotation of the wheel under machining and then, along the tooth line ( in the case of helical teeth, it is also necessary to couple the toothed wheel rotation around its own axis). The working motion of the tool in the direction tangent to the tooth outline begins and terminates in predetermined points defining the allowance left after the previous pass. Fig. 5 shows the way of determining the points of beginning and termination of machining. The arrows show the directions of the previous passes. The straight line, $i-1$, defines the direction of the tool motion in the previous pass; straight line, $i$, defines the direction of the currently considered pass. The hatched area presents the allowance machined in the considered pass; points $a$ and $b$ present the places of the tool getting into the allowance and out of the allowance, respectively. The points of tangency, discussed earlier, have been denoted as $P_{i}$ and $P_{i-1}$ for the currently considered and previous pass, respectively.

It can be seen in Fig. 5 that the sections defining the actual teeth outline are not located between the points of tool tangency but between the points of machining start and termination ( $a$ and $b$ ). Nevertheless, the location of the points of tangency directly influences the length of the cutting sections. The above geometrical assumptions are valid only for involute teeth outline. In the case of machining a space bottom, the tool corner is assumed to be tangent to the teeth base circle.

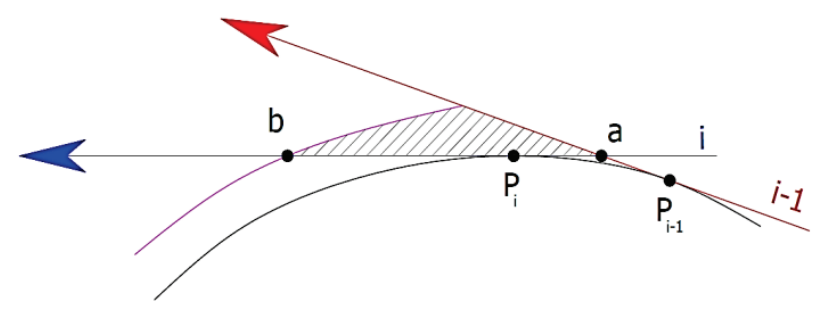

Figure 5 Determination of the machining path in a single pass

Additional possibilities of the elaborated mathematical model are: modification of the tooth point outline on the predetermined length and depth, as well as modification of the tooth within its root. Apart from the above, the possibility of performing shearing of the teeth top corners allows for avoiding changes of disengagement conditions during operation due to the error of radial runout of the teeth, $F$, in relation to the gear wheel hole. A significant advantage is the possibility of introducing both linearly and unlinearly variable outline modifications, for example, in order to machine teeth with not circular pitch curve.

The way of mathematical modelling discussed above, whose purpose is to determine the subsequent positions of the tool during machining, assumes machining of one 
tooth side. Acquisition of the positions for the opposite side is an effect of transformation of coordinates determining the linear position of the tool in relation to the tooth outline and gear wheel rotation around its own axis.

\section{TECHNOLOGICAL CHARACTERISTICS OF THE ELABORATED METHOD}

Apart from the determination of the tool motions in the plane perpendicular to the gear wheel axis, there is the problem of machining along the tooth line. In order to reduce the time of machining, long approaches and exits of the disk tool resulting from is relatively large diameter have been given up and radial entering and exit from the material for each pass have been adopted (as in Fig. 5). When the tool reaches the assumed depth along the tooth outline, the tool performs a motion along the tooth line. In the case of gears with cylindrical teeth, it is just a linear motion in one axis; in case of helical teeth, rotation of the machined wheel around its axis is added. Fig.6 shows the kinetics of tooth forming with the mutual positioning of the gear being machined and the machine tool fixed headstock. Combination of the motion along helical trajectory, with the pitch of $p z$ is effected by simultaneous linear motion along axis $Z$ and rotation in accordance with axis $C$. The inclination of the fixed headstock in axis $B$ is aimed at setting the tool in accordance with the direction of the teeth line inclination. In the case of machines where, instead of the fixed headstock only the object (the vice) can be inclined, the described method can also be applied.

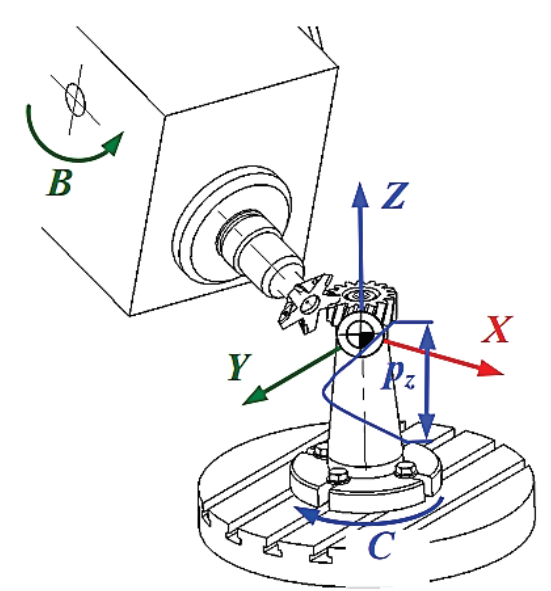

Figure 6 The proposed method machining kinetics

After a predetermined allowance is machined on one side of a given tooth, the wheel is repositioned (pitch motion) for machining of the subsequent tooth. It is worth stating that the method under discussion allows for machining not complete teeth, i.e. ones which are not present on the whole wheel circumference. Of course, such a case is feasible by the classical orbital methods but, unlike the present methods it often results in not completely machined spaces. In the case of the method under discussion, the spaces can be machined in any sequence or with omission of some selected ones. Fig. 7 shows the proposed strategy of machining the sides of the individual teeth.

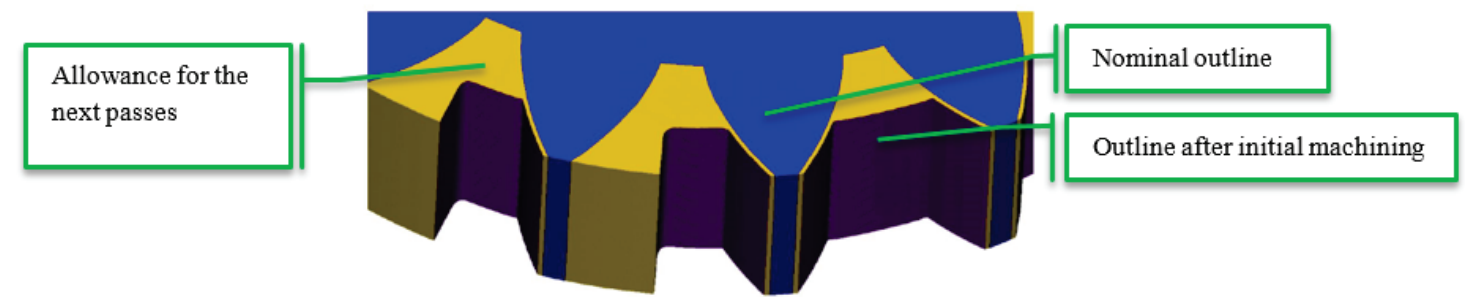

Figure 7 Example of space machining sequence. On the left: two spaces machined on one side of a tooth. On the right: one full space machined to the predetermined depth. Yellow colour- the remaining allowance

The requirements concerning the kinetic system of the machine on which the method is to be applied are defined for the general case that is for machining a helical tooth gear wheel. Cylindrical gear wheels are considered as a special case of helical ones when the tooth line inclination angle is equal to 0 . The machine tool should enable linear motions in 3 linear perpendicular axes and in two rotational axes, one around the gear wheel axis, the other perpendicular to it. The first of the rotational axes must be numerically controlled because it participates in the combination of the tool motions and in the pitch motion. The other rotational axis is used only to adjust the tooth axis inclination angle and it is reconfigured only once in the process of machining in order to enable the tool to get to the opposite sides of the teeth.

An important thing prior to the process of machining teeth is precise fixing of the teeth to be machined in relation to the rotational axis of the machine (rotational table). Run-out resulting from the rotational table misalignment and misalignment of the gear wheel axis results in the teeth outline run-out in relation to the gear wheel hole. In the tests performed with the application of the method under discussion, the gear wheel has been mounted in a special fixture which has been set on the rotational table; then, with the use of a dial indicator, mounted on the machine spindle, the fixture has been set precisely in the axis of the table rotation. The fixture has been specially designed for the described application. The lack of a conical surface according to which the fixture could be based in the rotational table axis necessitates the alignment of the axis of the fixture with that of the machine tool table. The reason of such design of the fixture was technological difficulties in simultaneous execution of concentric cones and diameters in the device.

\section{COMPUTER ENVIRONMENT OF MACHINING SIMULATION AND PROGRAMMING}

In order to make it possible to prepare the controlling program and to enter the design parameters of the teeth to 
be machined, as well as the technological parameters of machining, the described mathematical model has been implemented in the program environment of National Instruments LabView. Using that software, a program has been elaborated whose task is to make teeth parameters to be entered and modified, to verify the correctness of the entered values, to detect errors and to generate controlling codes for numerical machines (G-code). The elaborated computer program has been provided with a legible interface (Fig. 8) which allows for transparent entering of all parameters defining the teeth, additional information concerning modification of some of its features, but also information relevant to machining itself, i.e. parameters of cutting speed, values of allowances and tool dimensions. Another discussed module of the interface is graphic windows showing views of the outlines under machining. In this module, there is information about theoretical errors of the outline projection and variability of the removed layer thickness. The last module of software is responsible for displaying and exporting control instruction for the numerical machine tool. An important advantage of the software is the way of generating the control code. The program is made up of known and standardized text instructions type $G$-code and it can be compiled on any numerical machine serving that widely known standard.

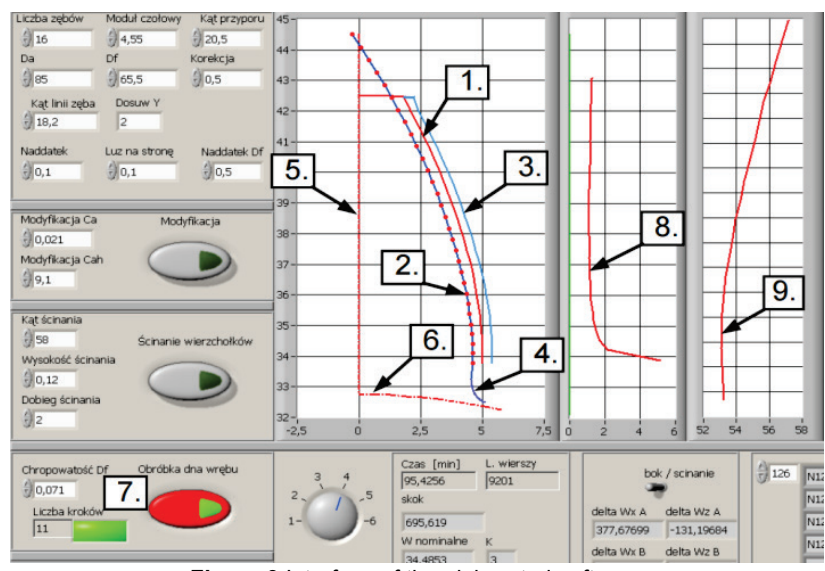

Figure 8 Interface of the elaborated software

Fig. 8 shows a view of an interface of the user of the elaborated software. In addition to the sections responsible for entering the data of the teeth to be machined, the program currently displays such information as the shape of the nominal teeth outline (1), envelope of the tooth side (2), tooth side outline with the allowance (3), the shape of the transition curve (4), toothy axis of symmetry (5), diameter of the spaces (6), as well as the magnitudes resulting from the stated machining parameters, i.e. the diagram of the theoretical tooth outline lobbing (8) and the diagram of the removed layer thickness (9). In addition to the above functions, an important one is that which allows for machining the space bottom or for the omission of it (7).

\section{APPLICATION OF THE ELABORATED METHOD AND ASSESSMENT OF THE MACHINING RESULTS}

In order to validate the method, complex machining of a series of 30 pairs of gears with the parameters defined in Tab. 1 has been performed. First, forming machining has been performed, followed by thermochemical treatment of the initially formed teeth. Gear wheels made of carburizing steel, $16 \mathrm{MnCr} 5$ have been carbonized to the depth of $1.1 \mathrm{~mm}$ and then hardened up to $67 \mathrm{HRC}$. The next stage was finish machining of the wheels in hard condition. In the machining, a multi blade head with 12 special AlTiN coated plates has been used (Fig. 1). The machining has been effected with the use of the milling centre, $D M U$ Monoblock 60.

Table 1 Parameters of the machined teeth

\begin{tabular}{|l|c|c|}
\hline & Pinion & Wheel \\
\hline Number of teeth & $z_{1}=16 \quad z_{2}=24$ \\
\hline Pressure angle & \multicolumn{2}{|c|}{$\alpha=20^{\circ}$} \\
\hline Width of teeth & \multicolumn{2}{|c|}{$b=20 \mathrm{~mm}$} \\
\hline Module & \multicolumn{2}{|c|}{$m=4.5 \mathrm{~mm}$} \\
\hline Outline shift coefficient & $x_{1}=0.5$ & $x_{2}=0$ \\
\hline Diameter of tops & $d_{\mathrm{a} 1}=82.457 \mathrm{~mm}$ & $d_{\mathrm{a} 2}=108.00 \mathrm{~mm}$ \\
\hline Pitch diameter & $d_{1}=72.00 \mathrm{~mm}$ & $d_{2}=118.365 \mathrm{~mm}$ \\
\hline Base diameter & $d_{\mathrm{f} 1}=62.385 \mathrm{~mm}$ & $d_{\mathrm{f} 2}=98.293 \mathrm{~mm}$ \\
\hline Distance of axes & \multicolumn{2}{|c|}{$a_{\mathrm{w}}=91.5 \mathrm{~mm}$} \\
\hline Normal clearance & \multicolumn{2}{|c|}{$j_{\mathrm{n}}=0.079 \mathrm{~mm}$} \\
\hline Machining allowance & \multicolumn{2}{|c|}{$q=0.14 \mathrm{~mm}$} \\
\hline Tooth line angle & \multicolumn{2}{|c|}{$\beta=18^{\circ}$} \\
\hline
\end{tabular}

Measurements of the manufactured gear wheels have been performed on the contact machine, Wenzel WGT600. The assessment concerned the geometrical parameters of the wheel according to which the given wheel was classified to a specific class of accuracy according to the standard, ISO 1328. Qualification of the test of 30 wheelpinion pairs to a specific class of execution according to ISO 1328 consisted in comparison of the measured deviations to the limit ones stated in the standard. The measurement results, together with the ascribed tooth class, are presented in Tab. 2. In cases when the deviations differed for the two sides of a tooth, the higher value has been presented.

Table 2 Measurement results and the assigned classes

\begin{tabular}{|c|c|c|c|c|c|}
\hline \multirow{2}{*}{\multicolumn{2}{|c|}{ Type of deviation }} & \multicolumn{2}{|c|}{ Wheel } & \multicolumn{2}{|c|}{ Pinion } \\
\hline & & \multirow{2}{*}{$\begin{array}{l}\text { Value } \\
(\mu \mathrm{m})\end{array}$} & \multirow{2}{*}{ Class } & \multirow{2}{*}{$\begin{array}{l}\text { Value } \\
\text { ( } \mu \mathrm{m})\end{array}$} & \multirow{2}{*}{ Class } \\
\hline$f_{\mathrm{f} \alpha}$ & Tooth outline shape & & & & \\
\hline$F_{\alpha}$ & Outline total & $2.1 \pm 1.1$ & 4 & $2.7 \pm 1.1$ & 4 \\
\hline$F_{\beta}$ & Tooth line & $3.1 \pm 1.6$ & 3 & $3.2 \pm 1.6$ & 3 \\
\hline$F$ & Summary pitch & $3.6 \pm 1.5$ & 4 & $3.8 \pm 1.6$ & 4 \\
\hline$F_{\mathrm{pt}}$ & Individual pitch & $9.4 \pm 3,7$ & 4 & $7.3 \pm 1.9$ & 3 \\
\hline$F_{\mathrm{r}}$ & Radial outline run-out & $4.3 \pm 2.2$ & 5 & $4.1 \pm 2.2$ & 5 \\
\hline
\end{tabular}

The presented measurement results of the deviations determining the teeth execution accuracy allow the manufactured wheels to be qualified to the $5^{\text {th }}$ class of accuracy. It can be concluded basing on the results, that qualification of the wheels to this class was due, first of all, to the individual pitch deviation, both in the case of the pinion and the gear wheel. In the case of the gear wheel, the deviation of the radial run-out has also reached class 5 . The obtained accuracies prove the correctness of the elaborated method, and, particularly, correct functioning of the proposed mathematical model and software. It should also be stated that among the set of 30 machined teeth pairs, there were ones whose deviations qualified them to classes 3 and 4 . Nevertheless, the 
achievement of the presented accuracies is very satisfactory for the mere fact that machining has been performed in a universal milling center, not a machine dedicated to highly precise machining. It can be supposed that the application of a more precise machine tool, e.g. a tool grinder, can reduce the recorded deviations and, consequently, qualify the manufactured gear wheels to higher execution classes.
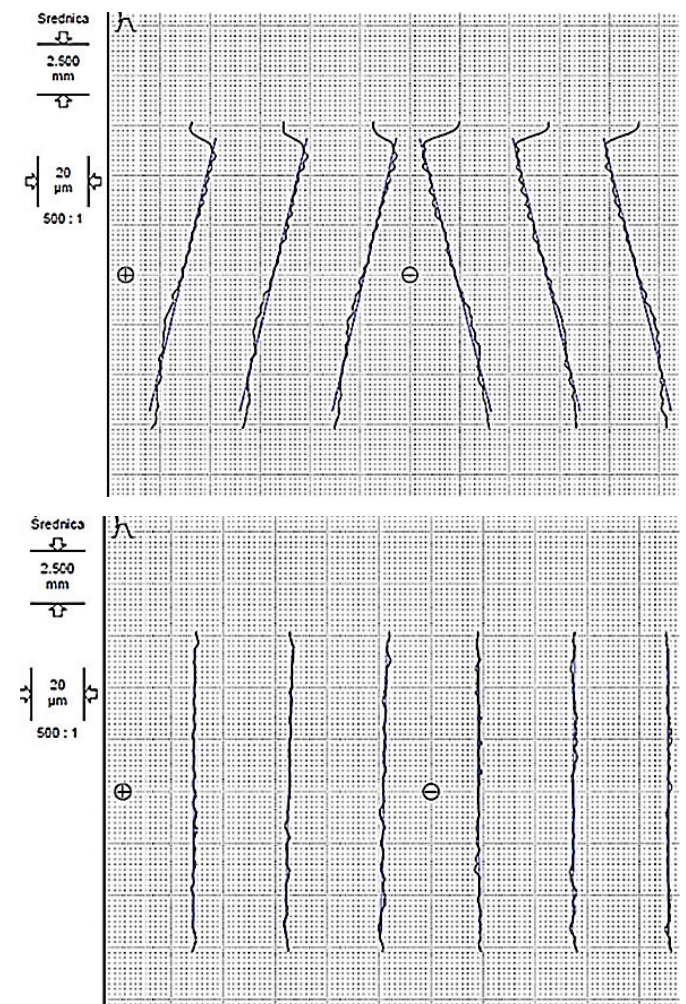

Figure 9 Outline deviations before (top) and after (bottom) introduction of the linear correction of the tool deflection

An important element of the discussion of the obtained results is the interpretation of the observed execution errors and their origin. In the introduction of the present work, tool deflection has been indicated as one of the major drawbacks of the known methods of teeth machining on universal machines. In the case of the measurements of the first machined teeth, characteristic, linear error of the tooth outline has been observed. The character of the measured outline deviation is much more linear, which has been shown in Fig. 10. In order to minimize the influence of the tool deflection on the accuracy of teeth execution, linear correction of the tool position has been introduced in the algorithm generating the machining paths. The effect of the operation is shown in Fig. 9. It can be seen that the undertaken action has significantly reduced the linear measured outline deviation from the nominal one. What is more, the implemented correction can easily be automated because, due to the mathematical modeling of the machining kinetics, the cross sections of the layer removed in each tool pass are known (Fig.4). Based on the known area of the removed layer cross section, machinability of the material being processed and the parameters experimentally determined for the given tool, one can estimate the tool deflection. In addition to the linear correction of the elaborated algorithm, it is also possible to introduce nonlinear correction in the form of a mathematical function or in the form of a correction table.

\section{DISCUSSION OF THE RESULTS AND INTERPRETATION OF THE ORIGIN OF ERRORS}

A separate issue, considered as another source of teeth execution inaccuracy, is thermal deformation of the machine and the tools. As the milling head warms up, its length will increase and, consequently, the accuracy of the wheel pitch will deteriorate. What is more, gradual warming of the tool during the process and rising coolant temperature (especially at the production beginning, before the machine reaches thermal stability), will lead to linear growth of the error. In the diagrams of the pitch error $\left(F_{p}\right)$, the described case has been recorded. In Fig. 10, it is clearly visible that the pitch deviation changes monotonously for the subsequent machined spaces and there is a characteristic leap in the pitch diagram between the first and the last space. This rapid change of deviation between the first and the last teeth is connected with change of tool temperature during machining; at the beginning the tool is cool and heats up during cutting. This change shown in Fig. 10 can be eliminated by performing warming up procedure for machine before manufacturing, in order to reach thermal stability both of machine and cutting tool. Thermal origin of the described inaccuracies is emphasized in Fig. 1 where a characteristic leap of the deviation value is visible. In the recorded case, before the space with the largest pitch deviation has been machined, the tool of the machine has been exchanged and an interoperation measurement by means of a contact probe has been performed. The break in the machining cycle has caused sudden cooling of the tool and resulted in the recorded error.

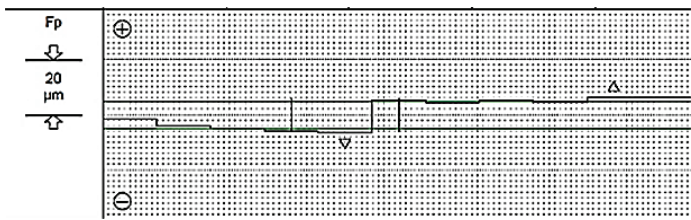

Figure 10 Change of the teeth pitch deviation with the increase of the tool temperature

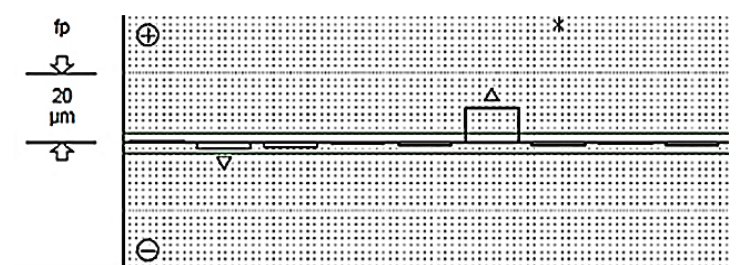

Figure 11 Stepping increase of the pitch error related to the tool cooling

In order to prove the hypothesis concerning the significant contribution of thermal deformations to the recorded execution errors, tests aimed at the assessment of the thermal deformations of the spindle of the machine had been performed (DMG DMU 60). Due to the friction resistance in the bearings and electric losses in the electric spindle, the spindle is a source of a significant quantity of heat. The electric spindle is cooled with a liquid, however, during operation, the spindle temperature can vary. The machine is also provided with thermal compensation of 
the spindle; it compensates thermal deformations. The tests consisted in measurement of the thermal deformations with a rotating spindle. In order to measure the thermal deformations, a measurement mandrel has been fixed in the spindle of the machine. On the table of the machine, the casing of a special device with contactless (induction) proximity detectors has been installed; the device measures relocations of the measurement mandrel in axes $X, Y$ and $Z$. In these tests, the spindle axis has been set horizontally for kinetic arrangement of the machine setting during machining. Diagrams showing the spindle relocations in the individual axes and its temperatures as a function of time can be seen in Fig. 12.

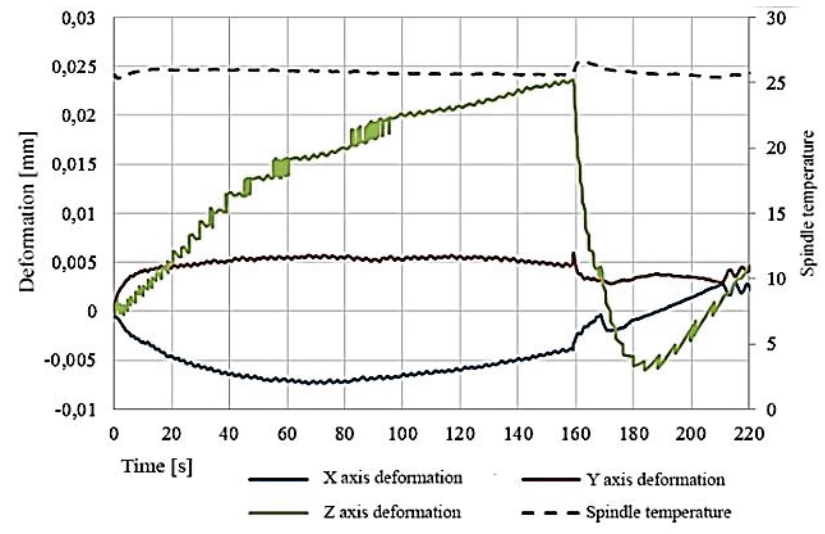

Figure 12 Deformation of machine axes caused by change in spindle temperature

The ambient temperature during the measurements was constant and amounted to about $35^{\circ} \mathrm{C}$. The spindle casing temperature rises for about 10 minutes at the beginning of the measurement cycle up to about $26^{\circ} \mathrm{C}$, then keeps constant till the rotation is stopped. After the rotation is stopped, the temperature grows up to about 27 ${ }^{\circ} \mathrm{C}$. This rapid growth of the casing temperature after the spindle is switched off is probably due to different cooling conditions (air flow from the rotating spindle). The recorded relocations in points in the $X$ and $Y$ direction are not large and do not exceed $0.010 \mathrm{~mm}$. On the other hand, relocation in axis $Z$ is significant and reaches the value of $0.023 \mathrm{~mm}$ after about 160 minutes of the spindle operation. Rapid relocation of the spindle in axis $Z$ can be observed after the spindle is switched off (reduction of the thermal deformation), as soon as after 10 minutes the spindle deformation returns to zero, then increases in the opposite direction to the value of about $-0.005 \mathrm{~mm}$ and slowly gets back to zero. There is a characteristic discontinuity of the curve of thermal deformation in axis $Z$. It is probably an effect of thermal compensation. In the spindle, a temperature sensor is fixed which measures the spindle temperature with too little resolution of $0.5{ }^{\circ} \mathrm{C}$. Each temperature variation caused stepping change of the diagram curve (due to compensation). As one can see in Fig. 12, the most significant thermal relocations of spindle occur in $Z$ axis, which is coincidental with the tool's axis. This fact leads to machining errors connected with the tool's length variation, what can be proved by formerly described trends (Fig. 10 and Fig. 11).

Another aspect influencing the accuracy of machining is the tool wear. Gradual changes of the tool diameter due to the wear of the cutting edge and the plate corner cause errors growing with the time of the tool operation. In order to asses the tool wear contribution to the ultimate execution errors, testing of the cutting edge wear during machining has been performed. The test has made it possible to determine the wear curve for the applied tool.

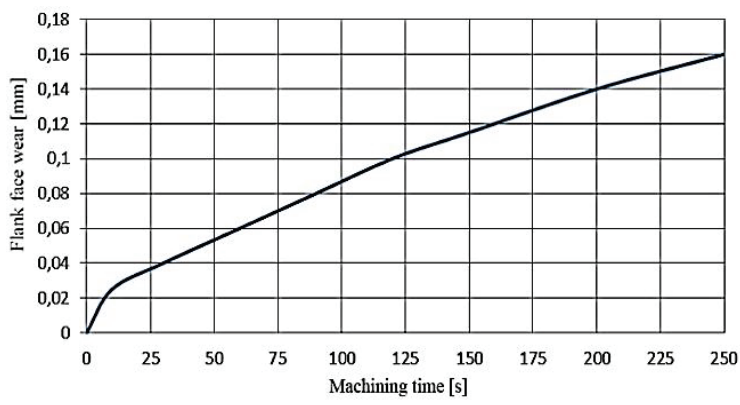

Figure 13VB wear curve of the flank face of the cutting plate

The investigation consisted in the measurement of wear traces appearing on the plates of the head during operation. The measurements have been performed with the use of a dedicated microscope for the assessment of cutting tools (Zeiss Stereo Discovery). The test results have been presented in the form a diagram of the flank face wear as a function of the cutting time in Fig. 13. It should be kept in mind that the wear of the flank face, designated $V B$, does not directly influence the withdrawal of the cutting edge (variation of the tool diameter). For the adopted clearance angle of $10^{\circ}$, the wear, $V B=0.15$, causes effective withdrawal of the cutting edge by about $0.026 \mathrm{~mm}$. During the performed wear tests, the tool made of boron nitride has been removing about $1350 \mathrm{~mm}^{3}$ of the material. The machining was performed at the cutting speed of $v_{c}=200 \mathrm{~m} / \mathrm{min}$, feed of $f_{z}=0.15 \mathrm{~mm}$. The milling head consisted of 12 edges and its diameter was $68 \mathrm{~mm}$.

In the opinion of authors, the conducted tests are versatile and comprehensive because of the standard, multi-purpose machine application. Reproducibility of the whole experiment is considered as easily achievable. The developed method assumes application of machining centre of standard kinematics, so experiment can be replicated on most of 5-axis NC machine tools. Because of the fact that developed software generates controlling program consisting of simple, standardized G-codetrext instructions, there are no special requirements for machine controlling unit and its software. Most of modern machine tools are capable of interpreting $G$-code type instructions.

\section{CONCLUSIONS}

Based on the effects of the application of the elaborated method of machining teeth presented in chapters 5 and 6 , one can formulate the following conclusions:

- The elaborated method allows for performing complete machining of cylindrical gear wheels with helical teeth in the $5^{\text {th }}$ class of accuracy according to ISO 1328. Machining can be successfully performed in material of raised hardness after heat treatment. These results are considered as satisfying and highly competitive to known methods.

- As shown by the results of the error origin analysis, the character of the deviations under discussion is close to linear (cf. Fig.9). Such character of variability of those errors facilitates significant 
compensation of them in the algorithm generating the machining paths. Nevertheless, the best effects of the compensation can be achieved only after thorough measurements of a number of geometrical parameters of the teeth. Information about the values and character of the deviations allows us to make decision concerning compensation of the errors at the stage of preparing the control program.

- Thanks to the parametrical form of the elaborated mathematical model, it is possible to compensate the errors resulting from the thermal deformation of the tool, its deflection and withdrawal of the cutting edge. What is necessary for correct compensation at the stage of generating the controlling code for the machine is execution of a number of technological tests.

- The elaborated method can be successfully applied on a machine which does not require modifications of the kinetic structure or any other adaptation except providing an adequate fixture and tool

- The control program generated with the use of the elaborated mathematical model has the form of Gcode instruction, which allows the method to be applied on a machine tool regardless of control system. The only requirement is compatibility of the control system with the widely known standard, Gcode (ISO 6983). This feature of the elaborated system of teeth machining significantly improves the universality of the method

- The possibility of modification of many design parameters of teeth (as, for example, addendum cutoff and the shape of the transition curve) and technological parameters (number of passes, error compensation) improves the possibilities of applying the method in machining various teeth and adaptation of the parameters to the specific requirements of use.

\section{REFERENCES}

[1] Yang, X. (2014). Research on manufacturing method of CNC plunge milling for spur face-gear. Journal of Materials Processing Technology, 214(12), 3013-3019. https://doi.org/10.1007/s00170-015-7417-3

[2] Tang, Z. P., Sun, J. P., Yan, L. \& Zou, F. (2017). Dynamic Contact Analysis and Tooth Modification Design for EMU Traction Gear. International Journal of Simulation Modelling, 16(4), 742-753. https://doi.org/10.2507/IJSIMM16(4)CO20

[3] Felten, K. \& Johnston, M. (1995). New concepts in CNC gear shaping. Gear Technology, 5, 22-26.

[4] Li, X. Y., Wang, N. N., Lv, Y. G., Zeng, Q. L. \& Hidenori, K. (2016). Tooth Profile Modification and Simulation Analysis of Involute Spur Gear. International Journal of Simulation Modelling, 15(4), 649-662. https://doi.org/10.2507/IJSIMM15(4)6.358

[5] Albert, M. (2009). Cutting gears on machining center. Gear Technology, 9, 14-16.

[6] Albert, M. (2013). Changing the landscape of gear production. Modern Machine Shop, 9, 17-23.

[7] Chibing, H. \& Weiming, T. (1997). Key techniques in CNC gear machining. Journal of Gansu University of Technology, 2, 42-44. https://doi.org/10.4028/www.scientific.net/AMM.217-219.1769

[8] Ozel, C. \& Inan, A. (2003). An investigation on manufacturing of the straight bevel gear using end mill by CNCmilling machine. Journal of Manufacturing Science and Engineering. 127(5), 503-511. https://doi.org/10.1115/1.1863256

[9] Suzler, G. (1986). Economics of CNC gear hobbing. Gear Technology, 3, 42-46.

[10] Yang, X. \& Tang, J. (2014). Research on manufacturing method of CNC plunge milling for spur face-gear. Journal of Materials Processing Technology, 214(12), 3013-3019. https://doi.org/10.1016/j.jmatprotec.2014.07.010

[11] Klocke, F., Brumm, M. \& Staudt, J. (2015). Quality and surface of gear manufactured witch free-form milling with standard tools. Gear Technology, 1, 64-69.

[12] Deng, X. \& Li, G. (2013). Face-milling spiral bevel gear tooth surfaces by application of 5-axis CNC machine tool. The International Journal of Advanced Manufacturing Technology, 71(5), 1049-1057. https://doi.org/10.0007/s00170-013-5499-3

[13] Suha, S., Leeb, E., Kima, H. \& Choa, J. (2002). Geometric error measurement of spiral bevel gears using a virtual gear model for STEP-NC. International Journal of Machine Tools and Manufacture, 42(3), 335-342. https://doi.org/10.1016/S0890-6955(01)00130-4

[14] Kawasaki, K. \& Shinma, K. (2008). Accuracy Measurement and Evaluation of Straight Bevel Gear Manufactured by End Mill Using CNC Milling Machine. Journal of Mechanical Design, 131(1), 64-71. https://doi.org/10.1115/1.2988480

[15] Krolczyk, G., Legutko, S. \& Raos, P. (2013). Cutting wedge wear examination during turning of duplex stainless steel. Tehnički Vjesnik - Technical Gazette, 20(3), pp. 413418. https://doi.org/621.9.025.5.029:621.385.833

[16] Simunovic, G., Simunovic, K. \& Saric, T. (2013). Modelling and Simulation of Surface Roughness in Face Milling. International Journal of Simulation Modelling, 12(3), 141-153. http://dx.doi.org/10.2507/IJSIMM12(3)1.219

[17] Maruda, R., Legutko, S., Krolczyk, G., Hloch, S. \& Michalski, M. (2015). An Influence of Active Additives on the Formation of Selected Indicators of the Condition of the Z10CrNi18-8 Stainless Steel Surface Layer in MQCL Conditions. International Journal of Surface Science and Engineering, 9(5), 452-465. https://doi.org/10.1504/IJSURFSE.2015.072069

[18] Tamang, S. K. \& Chandrasekaran, M. (2015). Modeling and optimization of parameters for minimizing surface roughness and tool wear in turning $\mathrm{Al} / \mathrm{SiCp} \mathrm{MMC}$, using conventional and soft computing techniques. Advances in Production Engineering \& Management, 10(2), 59-72. http://dx.doi.org/10.14743/apem2015.2.192.

[19] Hreha, P., Radvanska, A., Knapcíkova, L., Krolczyk, G., Legutko, S., Krolczyk, J., Hloch, S. \& Monka, P. (2015). Roughness parameters calculation by means on-line vibration monitoring emerging from AWJ interaction with material. Metrology and Measurement Systems, 22(2), 315326. https://doi.org/10.1515/mms-2015-0024

[20] Lane, T. \& Hughes, R. (1952). A study of the oil-film formation in gears by electrical resistance measurements. British Journal of Applied Physics, 10(3), 315-316. https://doi.org/10.1088/0508-3443/3/10/305

\section{Contact information:}

Rafal TALAR, PhD. MSc. Eng

Piotr JABLONSKI, MSc. Eng. (Corresponding author)

Wojciech PTASZYNSKI, PhD. MSc. Eng.,

Institute of Mechanical Technology,

Faculty of Mechanical Engineering and Management,

Poznan University of Technology

Maria Sklodowska-Curie Square 5, 60-965 Poznan, Poland

E-mail: rafal.talar@put.poznan.pl

E-mail: piotr.le.jablonski@doctorate.put.poznan.pl

E-mail: wojciech.ptaszynski@put.poznan.pl 